\title{
DNA Analysis on Oreochromis Niloticus
}

\author{
Sargis Pizzelli \\ Genetics and Cytology Department, Faculty of Biology, Yerevan State University, \\ Republic of Armenia
}

\begin{abstract}
This study aimed at investigating the tilapia fish (Oreochromis Niloticus) DNA. In analyzing Tilapia DNA, DNA extraction was carried out and PCR mixture was used for $20 \mu \mathrm{L}$ of reaction, making Master Mix such as $1 \mu \mathrm{L}$ Forward Primer, $1 \mu \mathrm{L}$ Reverse Primer, $10 \mu \mathrm{L}$ HotStar Taq Master Mix, $1 \mu \mathrm{L}$ DNA Sample, $7 \mu \mathrm{L}$ Nuslease Free Water. Mixing is done by adding the enzyme at the last stage. Then turn on the thermal cycler and set it according to the desired PCR conditions. Electrophoresis is carried out through stages such as PreDenaturation, Denaturation, Annealing, Extention, Final extension. The results showed that the virus did not infect tilapia (Oreochromis Niloticus). Tilapia sprayed on the gills with various doses showed the same results, namely no detection of KHV in mucus, kidneys, and liver.
\end{abstract}

Keywords: DNA, Oreochromis Niloticus, Extraction

Received : August 17, 2020

Received in Revised: August 25, 2020

Accepted: August 28, 2020

\section{Introduction}

Genetics is the study of various aspects related to the inheritance of traits and variations in traits in organisms and sub-organisms (such as viruses and prions). The benefits of genetics include knowing hereditary traits and every creature that lives in our environment, knowing hereditary disorders or diseases and efforts to overcome them, exploring a person's hereditary traits (for example blood type). The principle of genetics also needs to be mastered when studying a person's psychological or nervous traits which are determined by hereditary traits, for example the excess of one type of chromosome which is related to mental disorders which results in a person being asocial and criminal. Genetics has a very broad scope, which is academic and practical, including, among others, the role of chromosomes, the inheritance of genetic traits and anthropological traits (Crawford, 2018; Jobling et al, 2013; Segrè, 2010; Meyer, 2010).

DNA analysis is a relatively new technique and is developing rapidly in accordance with the increase in the quality and quantity of crime as well as being used in determining family relationships. A very potential method that is currently widely accepted as a means of identification in the forensic field and only requires a small sample (Corcoran \& Chabner, 2018).

Polymerase Chain Reaction (PCR) is an enzymatic method for DNA amplification in vitro. In the PCR process, several main components are needed, namely printed DNA, primary oligonucleotide, deoxyribonucleotide triphosphate (dNTP), DNA polymerase enzyme, and other supporting components are buffer compounds. In the PCR process using a thermocyclic tool. A machine that has the ability to heat and cool the test tube and adjust the temperature for each reaction stage. There are three important stages in the PCR process which are always repeated in 30-40 cycles and take place quickly, namely denaturation, anneling, and lengthening of the DNA strands. PCR products can be identified by their size. 
PCR allows DNA multiplication between two primers, only in a test tube, without the need to enter it into cells (in vivo). The PCR process requires double-stranded DNA which functions as a template containing DNA-targets (to be amplified) for the formation of new DNA molecules, DNA polymerase enzymes, deoxynucleoside triphosphate (dNTP), and a pair of oligonucleotide primers. Under certain conditions, both primers will recognize and bind to the complement DNA strands located at the beginning and end of the target DNA fragment, so that the two primers will provide free hydroxyl groups on carbon 3 '. After the two primers attach to the template DNA, DNA polymerase catalyzes the elongation process of the two primers by adding a nucleotide that complements the template nucleotide sequence. DNA polymerase catalyzes the formation of a phosphodiester bond between the $\mathrm{OH}$ on carbon 3 'and the 5' dNTP phosphate group added. So the process of adding dNTP which is catalyzed by the DNA polymerase enzyme takes place in the $5^{\prime} \rightarrow 3^{\prime}$ direction and is called the polymerization reaction. The DNA polymerase enzyme will only add dNTP which complements the nucleotides contained in the template DNA chain (Mahmoud et al, 2017)

Based on the description above, it can be seen that DNA analysis aims to determine identification in the forensic field. Polymerase Chain Reaction uses a machine that has the ability to heat and cool the test tube and adjust the temperature for each reaction stage. There are three important stages in the PCR process which are always repeated in 30-40 cycles and take place quickly, namely denaturation, anneling, and lengthening of the DNA strands. Under certain conditions, the two primers will recognize and bind to the complement DNA strands located at the beginning and end of the target DNA fragment.

The morphology of the tilapia fish body width of tilapia (Oreochromis niloticus) is generally $1 / 3$ of its body length. The body shape is elongated and slender, the scales of tilapia are relatively large, the eyes are protruding and large with white edges. Tilapia has 5 fins on the back, chest, stomach, anus and tail. The anal fin has 3 hard radii and 9-11 weak fin radii. The caudal fin has 2 weak hardened fingers and 16-18 weak fin radii. The dorsal fin (dorsal fin) has 17 hard fin radii and 13 soft fin radius. While the pectoral fin (pectoral fin) has 1 hard fin radius and 5 weak fin radius. The ventral fin has 1 hard fin radius and 5 weak fin radii. Tilapia have cycloid scales that cover their entire body from tail to head (Osman et al, 2017).

Tilapia are omnivorous animals that eat plants and other animals. When cultivated, tilapia also eat aquatic plants that grow in ponds. If they have reached adult size, these fish can be given a variety of additional feed such as pellets. Tilapia can live in freshwater, brackish water, and salt water with salinity between $0-35$ per mile. Tilapia can also be cultivated in relatively narrow yards from lowlands to highlands. For growth and reproduction, tilapia requires an optimum temperature, which is around $25-30^{\circ} \mathrm{C}$. salinity or salinity greatly affects the life of tilapia. Tilapia can grow and reproduce in waters with a salinity of $0-29 \%$ (promi), and can still grow at a salinity of $29-35 \%$ but cannot reproduce properly.

DNA is a type of biomolecule that stores and encodes the genetic instructions of every organism and many types of viruses. These genetic instructions play an important role in growth, development, and viruses. DNA is the nucleic acid along with proteins and carbohydrates, nucleic acids that are systematically arranged and are the carriers of genetic information passed on to the bodies of their offspring. Genetic information is arranged in the form of codons (codon) which are three pairs of nucleutide bases and determine the shape, structure, and physiology of a body. The chemical composition of macromolecules consists of three kinds of molecules, namely pentose sugar, phosphoric acid, and nitrogenous bases, which are mostly present in the living nucleus. DNA has a very important role in living bodies (Wang, 2019).

\section{DNA Structure}


The structure of DNA is a double helix composed of two polynucleotide strands connected to each other by weak hydrogen bonds, the hydrogen bond formed between two nitrogen bases, purine and pyridine, which are mutually coupled. Nucleic acids are composed of neuclottides which consist of sugar, phosphate and nitrogenous bases. Sugar is a pentose, namely deoxyribose and phosphate in the form of $\mathrm{PO}_{4}$, while nitrogenous bases are differentiated into pyrimidines (Cytosine and Thymine) and purines (Adenine and Guanine).

In 1953 Watson and Crick suggested that most DNA molecules have the shape of a double helix spiral. The nitrogenous base is connected to a deoxyribose sugar on the DNA back chain, the ribose sugar, that is, with 5 carbon atoms. On the DNA back chain, deoxyribose sugar is connected to a phosphate group. The rows of deoxyribose and phosphate sugars that make up the spiral band are the backbone of the DNA molecule. The nitrogenous base is related to sugar.

In the nucleotide sequence, the phosphate is located between the sugar molecules in such a way that it binds to $3^{\circ} \mathrm{C}$ of one sugar molecule and to $5^{\circ} \mathrm{C}$ of the next sugar molecule. These components, namely nitrogen, deoxyribose sugar and phosphate groups, form a molecule called a nucleotide. This phosphate compound is known as a covalent ester compound, so it is very strong. After the sugar-phosphate backbone is formed, the base occupies a fixed place, which is at $1^{\circ} \mathrm{C}$ of the pentose sugar. A ribbon and ribbon pair.

\section{DNA Function}

The function of DNA among other things: to identify genes, DNA is capable of storing genetic information and can pass this information precisely from parent to offspring. DNA in general can store and determine biological characteristics in living things in accordance with the arrangement of connections in very specific molecules. DNA is able to regulate the development of the phenotype of organisms. This means that genetic material must direct the growth and differentiation of organisms from the zygote to the adult individual. To regulate the development and metabolic processes of individuals and as separate particles in chromosomes (Rönn et al, 2013)

\section{Work Procedure}

\section{DNA Extraction}

The first step is to prepare the tools and materials. Use gloves before starting work. Cleaning samples from dirt adhering to the fish's body and then fixing them on $70 \%$ alcohol. If it will be detected from the host tissue, then cut the host tissue as much as $<20 \mathrm{mg}$ and do the scouring to destroy the tissue. Insert intact host or parasite tissue in a $1.5 \mathrm{~mL}$ microcentrifus and add $100 \mu \mathrm{L}$ of ATL buffer tube. Add $20 \mu \mathrm{L}$ proteinase $\mathrm{K}$, vortex to mix and incubate at $56^{\circ} \mathrm{C}$ in a shaking water bath for 3 minutes or preferably done overnight (overight). Centrifuge with spin down so that the liquid attached to the tube wall collects at the bottom of the tube. Add $200 \mu \mathrm{L}$ of buffer $\mathrm{Al}$ to the sample and vortex for 15 seconds, then incubate at $70 \mathrm{C}$ for 10 minutes. Furthermore, centrifuge with spin doown. Add $200 \mu \mathrm{L}$ of ethanol (96 $100 \%$ ) to the sample and then vortex for 15 seconds. Centrifuge with spin down $\mathrm{h}$.

Carefully transfer the sample from the micro tube into the QiaAmp mini spin column, cover then centrifuge at a speed of $8,000 \mathrm{rpm}$ for 1 minute. Transferring the QiaAmp mini spin column to the new collection tube, remove the tube containing the filtrate. Add $500 \mu \mathrm{L}$ of AWI buffer to the QiaAmp mini column then centrifuge at 8,000 rpm for 1 minute. Move the QiaAmp mini spin column to the new collection tube, discard the tube containing the filtrate. Add $500 \mu \mathrm{L}$ of buffer AW2, centrifuge at 14,000 rpm for 1 minute. Remove the filtrate from the collection tube and place the QiaAmp mini spin column back in the same collection tube. 
Do the centrifuge again at $14,000 \mathrm{rpm}$ for I minute. Transfer the QiaAmp mini spin column to a sterile $1.5 \mathrm{~mL}$ microsentrifuge tube and discard the collection tube containing the filtrate. Add $100 \mu \mathrm{L}$ of nuclease free water/distile water to the spin column and incubate at room temperature for 1 minute then centrifuge at 8,000 rpm for 1 minute. Re-add $100 \mu \mathrm{L}$ of nuclease free water to the spin column incubation at room temperature for 1 minute, then centrifuge at 8,000 rpm for 1 minute. The total DNA obtained was $200 \mu \mathrm{L}$.

\section{PCR}

The first step to take is to use gloves. Prepare the PCR mixture for the $20 \mu \mathrm{L}$ reaction. Making Master Mixes such as $1 \mu \mathrm{L}$ Forward Primer, $1 \mu \mathrm{L}$ Reverse Primer, $10 \mu \mathrm{L}$ HotStar Taq Master Mix, $1 \mu \mathrm{L}$ DNA Sample, $7 \mu \mathrm{L}$ Nuslease Free Water. Mixing is done by adding the enzyme at the last stage. Then turn on the thermal cycler and set it according to the desired PCR conditions. Inserting the PCR tube into the thermal cycler. After that run the PCR. After completion, the PCR product can be stored in the refrigerator $4^{\circ} \mathrm{C}$ before electrophoresis.

\section{Electrophoresian PCR Products}

In the electrophoresis process in the electrophoresis device through stages such as PreDenaturation for 5 minutes with a temperature of $95^{\circ} \mathrm{C}$, Denaturation for 30 seconds with a temperature of $95^{\circ} \mathrm{C}$, Annealing for 30 seconds at $54^{\circ} \mathrm{C}$, Extention for 60 seconds with a temperature of $72^{\circ} \mathrm{C}$, Final extension for 5 minutes at $72^{\circ} \mathrm{C}$. Next, use gloves and prepare a $1.5 \%$ agarose solution by adding $1.5 \mathrm{~g}$ agarose to $100 \mathrm{ml}$ TAE IX. Bring the sample to a boil then allow it to cool enough but not to freeze again. Pour in a mold equipped with a comb. Then let stand until frozen. After that, move the mold containing agarose which has been frozen into the electrophoresis machine. Fill it with TAE IX solution of the submerged agarose sample. Remove the comb carefully. Prepare a piece of parafilm as a container for mixing PCR products on a loading day.

Pipette as much as $3 \mu \mathrm{L}$ loading dye for each sample to be electrophoresed and placed on parafilm. Take $5 \mu \mathrm{L}$ of PCR product and mix it with the loading dye that has been previously placed on the parafilm. Perform pipetting repeatedly until the PCR product and loading dye are mixed. The PCR product pipette that has been mixed with loading dye and put it into the agarose well that has been made. Each sample is entered in different wells. On the far left of the well it is usually prepared for the marker/ladder, while the 1,2, 3 etc. are designated for the sample. The marker is inserted into the well without having to mix with loading dye. After finishing entering all the sampe and markers, the electrophoresis machine was tightly closed, the cable from the power was punched into the electrophoresis machine. The electrophoresis process was carried out at 100 volts for 30 minutes. Then the gel in the mold is removed and put into the GelRed staining solution for 10 minutes, rinse with distilled water. Conducting observations on the UV transiluminator to see whether there is a band on the desired bp size. Then photograph the gel to see the results.

\section{Results and Discussion}

PCR results on samples of gills, kidneys, and liver in various doses of immersion treatment did not show the presence of KHV. This shows that the virus does not infect tilapia (Oreochromis Niloticus) even though the KHV koi and carp can enter through the skin of the fish. Tilapia spray treated with various doses showed the same results, namely no detection of KHV in mucus, kidneys, and liver. In the examination of tilapia using the PCR method which was given injection treatment with KHV also showed negative results. 


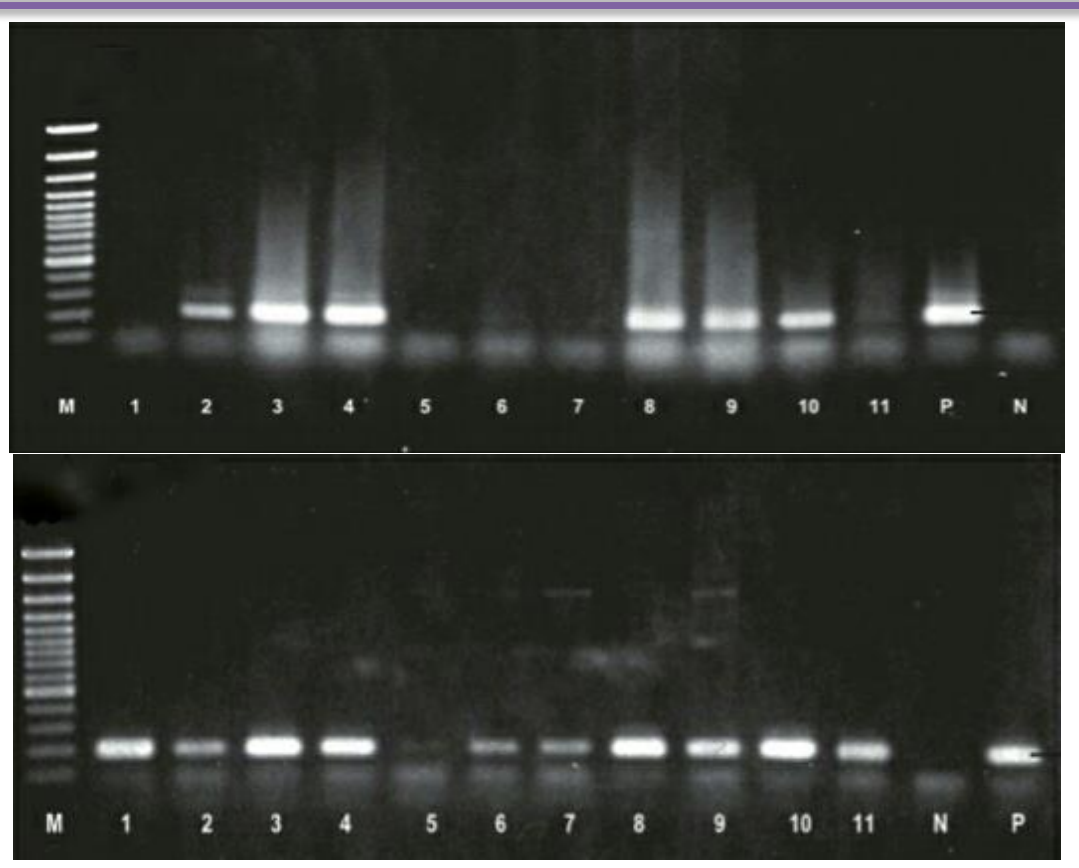

Figure 1. Electrophoresis results of tilapia gill and mucus samples in the immersion treatment

Tilapia (Oreochromis Niloticus) showed no clinical symptoms in the treatment of immersion, injection or gill spray with doses of 1 ID50, 10 ID50, 100 ID50 and 1000 ID50. Tilapia from each treatment dose was then examined using PCR to determine the presence of KHV DNA. The results of electrophoresis of PCR products can be seen in KHV not only attacking carp and koi fish, but also other freshwater fish such as tilapia. However, the clinical symptoms of fish that are attacked do not look like goldfish and koi fish. This can be seen from the results of this study which used a variety of different doses. The absence of clinical symptoms in tilapia is due to this virus having a very narrow host range.

Although tilapia did not show clinical symptoms, PCR results on mucus samples given a 1000 ID50 immersion dose and gill samples given a 1000 ID50 gill spray dose showed a faint / thin band that was parallel to the positive control. These results are the same as monitoring of KHV in tilapia in Tuban where externally tilapia attacked by KHV did not show clinical symptoms, but on laboratory examination there were bands that were parallel to the positive control. The PCR results also show a latent infection of the virus. One of the unique characteristics of all herpes viruses is the ability to form latent infections, which can be activated under a variety of stressful conditions. Viral latency is caused by many herpes viruses encoding genes that can modulate the host's immune response and circumvent the host's immune defenses. Two fish immune suppressor genes, TNFR and IL-10, can be encoded by the KHV genome. This suggests that immune modulation genes are stored and can play an important role in the fish's abilities.

Tilapia samples (Oreochromis niloticus) came from cases of death with a mortality of more than $50 \%$ in low salinity ponds in Karawang, West Java. Sick tilapia experiences symptoms of Streptococcocis, which are characterized by swirling and irregular swimming, bulging eyes, and a blackish body. As many as 3 fish were brought alive with the virus to avoid the immune system of the host. PCR results on samples of gills, kidneys and liver at various doses of immersion treatment did not show the presence of KHV. This shows that the virus does not infect tilapia even though the KHV koi and goldfish can enter through the skin of the fish. In addition to the virus entering, the skin can become the target tissue for the virus. Replication of KHV in the skin will facilitate infection to other individuals via the "skin to

Copyright $($ C 2020, International Journal Papier Advance and Scientific Review, Under the license CC BY-SA 4.0 
water to skin" or "skin to skin" routes. KHV infects the skin of the fish by reducing genes encoding several components of the mucosal barrier of the mucus layer, such as mucin 5B, AMP, beta defensin 1 and 2, and protein-claudin 23 and 30. Tilapia sprayed on the gills at various doses showed results. the same, namely not detected KHV in mucus, kidneys and liver. KHV that attacks koi and goldfish generally infects the gills.

The possibility that the virus will replicate on diseased gills and then enter the water is compatible with the rapid and efficient spread of this infectious disease. This is analogous to a respiratory virus in mammals that infects the respiratory epithelium, replicates there, and spreads via airborne droplets and aerosols. This may also be the most common way aquatic viruses spread. Tilapia treated with intraperitoneal injection, KHV DNA was not detected in mucus, gills, kidney and liver at various injection doses (1 ID50-1000 ID50).

In the examination of tilapia using the PCR method which was given injection treatment with KHV also showed negative results. The amplification results were detected by electrophoresis of each amplicon as much as $10 \mu \mathrm{L}$ on $1.5 \%$ agarose gel in $1 \mathrm{x}$ Tris-acetateEDTA buffer ( $220 \mathrm{~V}$ for 25 minutes). DNA staining was carried out by immersing the gel in ethidium bromide solution $(0.5 \mu \mathrm{g}$ per $100 \mathrm{~mL}$ TAE buffer) for 15 minutes and the results were documented with a polaroid camera. In this study, using tilapia (Oreochromis Niloticus) as research subjects showed that the fish were not infected with KHV and did not show clinical symptoms. This is because tilapia is a species that is able to tolerate various environmental conditions. Fish can still live in permissive temperatures.

\section{Conclusion}

Genetics is a branch of biology that is concerned with the inheritance of traits (heredity) and variation and also the reduction of the expression of traits to the next generation. DNA analysis is a relatively new technique and is developing rapidly with increasing quality and quantity of crime. To carry out this activity, a PCR tube that is responsive to temperature changes is needed and a thermal cycler engine, a machine capable of rapidly increasing and lowering the temperature, and materials for making PCR reactions. There are several stages in the use of electrophoresis, namely the extraction of the samples used, the extraction results such as DNA, RNA and protein are materials that will be used in the next process. The supporting media commonly used in electrophoresis are agarose gel, starch gel, polyacrylamide gel, and polyacetic cellulose paper. Agarose gel is commonly used for DNA and RNA in electrophoresis, while polyacrylamide gel is used for protein.

\section{References}

Corcoran, R. B., \& Chabner, B. A. (2018). Application of cell-free DNA analysis to cancer treatment. New England Journal of Medicine, 379(18), 1754-1765.

Crawford, M. H. (2018). Anthropological genetics. The International Encyclopedia of Biological Anthropology, 1-7.

Jobling, M., Hurles, M., \& Tyler-Smith, C. (2013). Human evolutionary genetics: origins, peoples \& disease. Garland Science.

Mahmoud, M. M., Schechter, A., Alnajjar, K. S., Huang, J., Towle-Weicksel, J., Eckenroth, B. E., ... \& Sweasy, J. B. (2017). Defective nucleotide release by DNA polymerase $\beta$ mutator variant E288K is the basis of its low fidelity. Biochemistry, 56(41), 55505559.

Meyer, B. J. (2010). Targeting X chromosomes for repression. Current opinion in genetics \& development, 20(2), 179-189. 
Osman, K. M., Al-Maary, K. S., Mubarak, A. S., Dawoud, T. M., Moussa, I. M., Ibrahim, M. D., ... \& Fawzy, N. M. (2017). Characterization and susceptibility of streptococci and enterococci isolated from Nile tilapia (Oreochromis niloticus) showing septicaemia in aquaculture and wild sites in Egypt. BMC veterinary research, 13(1), 357.

Rönn, T., Volkov, P., Davegårdh, C., Dayeh, T., Hall, E., Olsson, A. H., ... \& Jones, H. A. (2013). A six months exercise intervention influences the genome-wide DNA methylation pattern in human adipose tissue. PLoS Genet, 9(6), e1003572.

Segrè, A. V., Groop, L., Mootha, V. K., Daly, M. J., Altshuler, D., Diagram Consortium, \& Magic Investigators. (2010). Common inherited variation in mitochondrial genes is not enriched for associations with type 2 diabetes or related glycemic traits. PLoS Genet, 6(8), e1001058.

Wang, J., Wang, D. X., Tang, A. N., \& Kong, D. M. (2019). Highly integrated, biostable, and self-powered DNA motor enabling autonomous operation in living bodies. Analytical chemistry, 91(8), 5244-5251. 